\title{
Transapical aortic valve implantation in patients with severely depressed left ventricular function
}

\author{
Axel Unbehaun, MD, Miralem Pasic, MD, PhD, Semih Buz, MD, Stephan Dreysse, MD, \\ Marian Kukucka, MD, Roland Hetzer, MD, PhD, and Thorsten Drews, MD
}

\begin{abstract}
Objectives: Transapical aortic valve implantation significantly reduces operative risk in elderly patients with aortic valve stenosis and comorbidities. However, it is unknown whether this procedure is feasible in patients with advanced heart failure.
\end{abstract}

\begin{abstract}
Methods: Between April 2008 and July 2010, 258 patients underwent transapical aortic valve implantation. Twenty-one patients had advanced heart failure with decompensation and a left ventricular ejection fraction of $10 \%$ to $25 \%$. The mean age of these patients was $74 \pm 11$ years (range, $36-88$ years). The mean left ventricular ejection fraction was $20 \% \pm 5 \%$ (range, $10 \%-25 \%$ ). Mean logistic EuroSCORE was $66 \% \pm 21 \%$ (range, 27\%-97\%) and mean Society of Thoracic Surgeons score 33\% $\pm 25 \%$ (range, 4\%-90\%). Nine patients were operated on using femorofemoral cardiopulmonary bypass and 12 without.
\end{abstract}

Results: Technical success of the procedure was $100 \%$ with no conversion to conventional surgery. The mean time of cardiopulmonary bypass was $27 \pm 25$ minutes (range, 6-81 minutes). Postoperatively, the left ventricular ejection fraction increased to $38 \% \pm 12 \%$ (range, $20 \%-60 \%$ ). There were no postoperative neurologic complications. A new pacemaker implantation was needed in $2(10 \%)$ patients. The 30-day mortality was $4.8 \%$. Survival at $1,3,12$, and 24 months was $95 \%, 81 \%, 76 \%$, and $62 \%$, respectively.

Conclusions: Transapical aortic valve implantation can be performed safely in patients with decompensated heart failure or even in the presence of cardiogenic shock. (J Thorac Cardiovasc Surg 2012;143:1356-63)

Conventional aortic valve replacement has been the "gold standard" in the treatment of severe aortic valve stenosis with excellent confirmed results over decades. ${ }^{1}$ However, it is still a challenge in patients with advanced heart failure, in whom survival is markedly reduced regardless of the type of treatment. ${ }^{2,3}$ If acute cardiac decompensation or cardiogenic shock is present, percutaneous valvuloplasty as a bridge to aortic valve replacement ${ }^{4}$ or mechanical circulatory support and aortic valve replacement ${ }^{5}$ have been reported as treatment options. The prognosis of aortic valve stenosis is grave in patients who are not candidates for aortic valve replacement, regardless of the therapeutic strategy. ${ }^{6}$

Transcatheter aortic valve implantation (with a transfemoral, transapical, or transaxillary approach) has been introduced as an alternative to conventional aortic valve replacement for elderly and polymorbid patients. ${ }^{7-10}$ Transapical aortic valve implantation can be applied even in the presence of severe peripheral arterial disease, and there is the advantage of direct, short, and antegrade access to the aortic valve with possibly more precise

From Deutsches Herzzentrum Berlin, Berlin, Germany.

Disclosure: Professor Pasic and Drs Unbehaun, Drews, Buz, and Dreysse have been proctors to Edwards Lifesciences since July 2009. The other authors report no conflicts of interest with regard to commercial support.

Received for publication Oct 7, 2010; revisions received March 11, 2011; accepted for publication July 11, 2011; available ahead of print Aug 16, 2011.

Address for reprints: Miralem Pasic, MD, PhD, Deutsches Herzzentrum Berlin, Augustenburger Platz 1, 13353 Berlin, Germany (E-mail: pasic@dhzb.de). $0022-5223 / \$ 36.00$

Copyright (c) 2012 by The American Association for Thoracic Surgery doi:10.1016/j.jtcvs.2011.07.008 implantation of the prosthesis and a lower stroke rate. Excellent early results can be achieved if left ventricular performance is preserved. Presently, the reported 30-day mortality is between $5 \%$ and $12 \%$ in centers experienced in the procedure. ${ }^{11-16} \mathrm{~A}$ first report with a follow-up of up to 3 years in a limited number of patients and optimistic results has recently been published. ${ }^{17} \mathrm{~A}$ review of several advantages and serious complications of the transcatheter procedure in comparison with conventional surgery has recently appeared. ${ }^{18}$

Up to now, it is unclear whether transapical aortic valve implantation is a feasible option in the presence of advanced heart failure or cardiogenic shock. Here, we report our experience with transapical aortic valve implantation in 21 patients with poor left ventricular performance.

\section{PATIENTS AND METHODS \\ Patients}

Between April 2008 and July 2010, a total of 258 consecutive patients with severe aortic valve stenosis underwent transapical aortic valve implantation. In this retrospective study, patients were divided into 2 groups according to their preoperative left ventricular ejection fraction (LVEF). Group I (mean age, $74 \pm 11$ years; range, 36-88 years) consisted of 21 patients with an LVEF of $10 \%$ to $25 \%$ measured by preoperative transthoracic or transesophageal echocardiography. Group II (mean age, $80 \pm 8$ years; range, 37-99 years) served as controls and consisted of 237 patients with an LVEF of more than $25 \%$. The baseline characteristics of groups I and II are given in Table 1.

There were $12(57 \%)$ men and $9(43 \%)$ women in group I, the group with poor left ventricular performance. The mean logistic EuroSCORE for this group was $65.7 \% \pm 20.6 \%$, with a range from $26.9 \%$ to $96.7 \%$. 


\section{Abbreviations and Acronyms \\ $\mathrm{CPB}=$ cardiopulmonary bypass \\ $\mathrm{LVEF}=$ left ventricular ejection fraction}

The mean Society of Thoracic Surgeons score for group I was 33.3\% \pm $25.6 \%$, with a range from $3.8 \%$ to $89.5 \%$. All these patients were highly symptomatic and referred for at least urgent surgery on the aortic valve. Ten $(49 \%)$ of them had cardiogenic shock, needed intensive care unit treatment, and were dependent on catecholamine support at least after induction of anesthesia. Six (29\%) patients were receiving continuous epinephrine therapy with a dosage of 0.04 to $0.29 \mu \mathrm{g} \cdot \mathrm{kg}^{-1} \cdot \mathrm{min}^{-1}$. Two $(10 \%)$ patients needed continuous treatment with dobutamine $\left(4.2 \mu \mathrm{g} \cdot \mathrm{kg}^{-1} \cdot \mathrm{min}^{-1}\right.$ and $4.8 \mu \mathrm{g} \cdot \mathrm{kg}^{-1} \cdot \mathrm{min}^{-1}$ ) and phosphodiesterase III inhibitor (milrinone $0.19 \mu \mathrm{g} \cdot \mathrm{kg}^{-1} \cdot \min ^{-1}$ and $0.22 \mu \mathrm{g} \cdot \mathrm{kg}^{-1} \cdot \min ^{-1}$ ). One patient was receiving intra-aortic balloon counterpulsation, and in 2 others with cardiogenic shock the plan was to implant an intra-aortic balloon pump during the procedure. There were $6(29 \%)$ patients with new-onset acute renal failure owing to circulatory depression and 4 of them required hemodialysis. Seven $(33 \%)$ patients showed metabolic acidosis and $1(5 \%)$ needed respirator support.

The preoperative characteristics of the control group II are given in Table 1. In general, patients were considered for transapical aortic valve implantation if the logistic EuroSCORE was at least $20 \%$ or if the Society of Thoracic Surgeons score was $10 \%$ or higher. If the risk score values were lower, the patients were considered for the procedure only if there were specific pathologic conditions with high risk for conventional aortic valve surgery (eg, porcelain aorta). The only exclusion criteria were active valve endocarditis, an aortic valve annulus greater than $24 \mathrm{~mm}$, and bicuspid aortic valve morphology. According to our institutional "no exclusion policy," patients with a very high risk profile, poor left ventricular performance, or even profound shock were also considered for this type of treatment. ${ }^{15}$ Therefore, there are some patients in group I in whom the intervention on the aortic valve was considered an ultima-ratio attempt. All patients or their representatives gave informed consent. The mean follow-up was $10.4 \pm 7.9$ months (range, 1-27 months). No patients were lost to follow-up.

\section{Methods}

The preoperative examinations included clinical and blood examinations, electrocardiogram, chest radiograph, coronary angiography, transthoracic echocardiography, computed tomography of the chest (Figure 1) and pelvis, and ultrasound examinations (Doppler) of the peripheral and carotid arteries. In patients with hemodynamic instability, we waived computed tomography. Physical examination, neurologic clinical findings, transthoracic echocardiography, and the battery of blood examinations were repeated during the first week postoperatively or as long as the patient was in the hospital. Postoperative computed tomographic scans of the chest and the cranium were performed as a standard protocol in the first $200 \mathrm{pa}-$ tients but only exceptionally in the last 58 patients.

All procedures were performed in a hybrid operating room with a monoplane angiography system (Siemens Artis zee; Siemens AG, Munich, Germany). All valve implantations were performed by the same team consisting of 5 surgeons, 2 cardiologists, and 2 anesthesiologists with expertise in echocardiography dedicated to this program. A perfusionist and a heartlung machine were always present in the operating room and at least in a stand-by mode. In patients with advanced heart failure and for specific reasons (eg, short distance of the coronary ostia to the annulus), the connecting tubes for the heart-lung machine were placed on the table and ready to connect instantly. The elective use of cardiopulmonary bypass (CPB) was considered in patients with cardiogenic shock or poor left ventricular function (LVEF, 10\%-20\%). The femoral vein and the common femoral artery (or the axillary artery) were cannulated. It was decided preoperatively in these specific cases whether valve implantation had to be performed under a short duration of $\mathrm{CPB}$ or without starting up the heart-lung machine. Immediately before the procedure, the whole team analyzed the diagnostic workup and discussed possible technical difficulties and complications and the way to prevent them, as well as the use of the heart-lung machine. Elective coronary artery stent implantation was considered in patients with concomitant coronary artery disease. Only the most relevant coronary artery stenosis was considered to be a target for stent implantation. ${ }^{15}$ Concomitant atrioventricular valve disease was not treated simultaneously (except with grade IV regurgitation of the tricuspid valve).

All procedures were performed with the patient under general anesthesia. The procedure was performed through a left anterior minithoracotomy, usually in the sixth or seventh intercostal space. The left side of the chest was slightly elevated while the patient lay in the supine position. Valve preparation was started at the time of puncture of the femoral vessels and the incision on the chest. The principal surgical technique that has been described in detail by Walther and associates ${ }^{19}$ was applied in the first 20 patients. In all further cases, the valve was deployed according to our modification of the technique ("Berlin addition") that has been described in detail elsewhere. $^{20}$ Balloon-expandable transcatheter stent-prosthetic xenograft valves of 23- or 26-mm diameter with their delivering system (both Edwards SAPIEN THV; Edwards Lifesciences, Irvine, Calif) were used in all patients. The size of the valve used was determined according to the diameter of the native aortic valve annulus as measured by intraoperative transesophageal echocardiography. We chose a valve size of $23 \mathrm{~mm}$ for aortic valve annuli smaller than $21 \mathrm{~mm}$ and a $26-\mathrm{mm}$ prosthesis for annulus diameter of $21 \mathrm{~mm}$ and greater. The procedure was monitored by fluoroscopy, angiography, and intraoperative transesophageal echocardiography.

\section{Statistical Analysis}

Continuous variables are expressed as mean \pm standard deviation and maximal and minimal absolute numbers. Statistical analyses were carried out with the Student $t$ test, the $\chi^{2}$ test, or the Fisher exact test. A KaplanMeier survival function was calculated for each group. A Gehan test was used to analyze differences between 2 survival functions. A univariate logistic regression analysis was performed. The data were evaluated by SPSS software version 17.0 for Windows (SPSS, Inc, Chicago, Ill).

\section{RESULTS \\ Early Survival}

The 30-day survival for the whole group of 258 patients was $95.3 \%$ (overall early mortality, $4.7 \% ; 12$ patients died). The 30-day survival for group I (21 patients with an LVEF of $10 \%$ to $25 \%$ ) was $95.3 \%$ (early mortality, $4.8 \% ; 1$ patient died). In comparison, the 30-day survival for group II (237 patients with an LVEF above $25 \%$ ) was $95.4 \%$ (early mortality, $4.6 \% ; 11$ patients died). The cause of early death in group I was acute myocardial failure on the day of the operation in a patient with cardiogenic shock, acute renal failure, and preoperative adrenaline therapy. Besides an uneventful valve implantation, a myocardial recovery failed to appear even after intra-aortic balloon counterpulsation had been established. The causes of early deaths in group II were septicemia in 1 patient with preoperative methycillin-resistant Staphylococcus aureus, acute myocardial failure in 2, multiorgan failure in 4 , basilar vein thrombosis in 1 , abdominal complications in 2 , and leg ischemia related to severe peripheral arterial disease and type II heparin-induced thrombocytopenia in 1. 
TABLE 1. Preoperative characteristics in 258 patients

\begin{tabular}{|c|c|c|c|c|c|}
\hline Parameter & \multicolumn{2}{|c|}{$\begin{array}{c}\text { Group I }(\mathbf{n}=\mathbf{2 1}) \\
\mathbf{L V E F} \leq \mathbf{2 5} \%\end{array}$} & \multicolumn{2}{|c|}{$\begin{array}{c}\text { Group II }(\mathbf{n}=\mathbf{2 3 7}) \\
\text { LVEF }>\mathbf{2 5} \%\end{array}$} & $P$ value \\
\hline Age, year & \multicolumn{2}{|c|}{$74.2 \pm 10.8$} & \multicolumn{2}{|c|}{$79.8 \pm 7.9$} & .003 \\
\hline Male & $\mathrm{n}=12$ & $57 \%$ & $\mathrm{n}=67$ & $28 \%$ & .011 \\
\hline Body mass index, $\mathrm{kg} / \mathrm{m}^{2}$ & \multicolumn{2}{|c|}{$26.2 \pm 5.1$} & \multicolumn{2}{|c|}{$26.9 \pm 5.5$} & .592 \\
\hline Logistic EuroSCORE, \% & \multicolumn{2}{|c|}{$65.7 \pm 20.6$} & \multicolumn{2}{|c|}{$36.5 \pm 17.1$} & .001 \\
\hline STS score, $\%$ & \multicolumn{2}{|c|}{$33.3 \pm 25.6$} & \multicolumn{2}{|c|}{$18.5 \pm 13.6$} & .001 \\
\hline NT-proBNP, pg/mL & \multicolumn{2}{|c|}{$17103 \pm 17886$} & \multicolumn{2}{|c|}{$4387 \pm 6562$} & .001 \\
\hline NYHA class IV & $\mathrm{n}=16$ & $76 \%$ & $\mathrm{n}=63$ & $27 \%$ & .001 \\
\hline Cardiogenic shock & $\mathrm{n}=10$ & $48 \%$ & $\mathrm{n}=6$ & $3 \%$ & .001 \\
\hline Cerebral ischemic lesion(s) & $\mathrm{n}=10$ & $48 \%$ & $\mathrm{n}=66$ & $28 \%$ & .078 \\
\hline Diabetes mellitus & $\mathrm{n}=8$ & $38 \%$ & $\mathrm{n}=52$ & $22 \%$ & .107 \\
\hline Coronary artery disease & $\mathrm{n}=13$ & $62 \%$ & $\mathrm{n}=136$ & $57 \%$ & .819 \\
\hline Serum creatinine, $\mathrm{mg} / \mathrm{dL}$ & \multicolumn{2}{|c|}{$1.6 \pm 0.7$} & \multicolumn{2}{|c|}{$1.2 \pm 0.7$} & .034 \\
\hline COPD & $\mathrm{n}=8$ & $38 \%$ & $\mathrm{n}=105$ & $44 \%$ & .651 \\
\hline $\mathrm{FEV}_{1}, \mathrm{~L}$ & \multicolumn{2}{|c|}{$1.6 \pm 0.6$} & \multicolumn{2}{|c|}{$1.5 \pm 0.5$} & .567 \\
\hline Peripheral arterial disease & $\mathrm{n}=13$ & $62 \%$ & $\mathrm{n}=162$ & $68 \%$ & .627 \\
\hline Systolic PAP $\geq 50 \mathrm{~mm} \mathrm{Hg}$ & $\mathrm{n}=8$ & $38 \%$ & $\mathrm{n}=92$ & $39 \%$ & 1.000 \\
\hline Porcelain aorta & $\mathrm{n}=2$ & $10 \%$ & $\mathrm{n}=14$ & $6 \%$ & .627 \\
\hline Atrial fibrillation & $\mathrm{n}=5$ & $24 \%$ & $\mathrm{n}=79$ & $33 \%$ & .470 \\
\hline Pacemaker or ICD & $\mathrm{n}=3$ & $14 \%$ & $\mathrm{n}=23$ & $10 \%$ & .454 \\
\hline Previous CABG & $\mathrm{n}=5$ & $24 \%$ & $\mathrm{n}=37$ & $16 \%$ & .354 \\
\hline Previous AVR & $\mathrm{n}=1$ & $5 \%$ & $\mathrm{n}=13$ & $16 \%$ & 1.000 \\
\hline Previous MVR & $\mathrm{n}=1$ & $5 \%$ & $\mathrm{n}=6$ & $3 \%$ & .452 \\
\hline Mitral regurgitation $>$ grade 2 & $\mathrm{n}=3$ & $14 \%$ & $\mathrm{n}=14$ & $6 \%$ & .150 \\
\hline Tricuspid regurgitation $>$ grade 2 & $\mathrm{n}=2$ & $10 \%$ & $\mathrm{n}=8$ & $3 \%$ & .191 \\
\hline LVEF, \% & \multicolumn{2}{|c|}{$20.4 \pm 5.3$} & \multicolumn{2}{|c|}{$52.9 \pm 10.5$} & - \\
\hline LVEDD, mm & \multicolumn{2}{|c|}{$57.3 \pm 8.6$} & \multicolumn{2}{|c|}{$48.3 \pm 6.9$} & .001 \\
\hline Mean aortic valve area, $\mathrm{cm}^{2}$ & \multicolumn{2}{|c|}{$0.8 \pm 0.3$} & \multicolumn{2}{|c|}{$0.6 \pm 0.1$} & .006 \\
\hline Mean dP, mm Hg (TTE) & \multicolumn{2}{|c|}{$33.1 \pm 13.5$} & \multicolumn{2}{|c|}{$50.2 \pm 13.8$} & .001 \\
\hline Aortic regurgitation $>$ grade 2 & $\mathrm{n}=1$ & $5 \%$ & $\mathrm{n}=16$ & $7 \%$ & 1.000 \\
\hline Annulus, mm & \multicolumn{2}{|c|}{$22.3 \pm 1.0$} & \multicolumn{2}{|c|}{$22.3 \pm 1.3$} & .950 \\
\hline
\end{tabular}

Boldface indicates $P<.05 . L V E F$, Left ventricular ejection fraction; STS, The Society of Thoracic Surgeons; $N T$-proBNP, $N$-terminal pro-brain natriuretic peptide; $N Y H A$, New York Heart Association; $C O P D$, chronic obstructive pulmonary disease; $F E V_{l}$, forced expiratory volume in 1 second; $P A P$, pulmonary artery pressure; $I C D$, implantable cardiac defibrillator; $C A B G$, coronary artery bypass grafting; $A V R$, aortic valve replacement; $M V R$, mitral valve repair or replacement; $L V E D D$, left ventricular end-diastolic diameter; $d P$, transvalvular gradient; TTE, transthoracic echocardiography.

\section{Procedural Course in Group I}

We chose a $23-\mathrm{mm}$ valve in $4(19 \%)$ patients and a $26-\mathrm{mm}$ prosthesis in $17(81 \%)$ patients. During the same procedure $1(5 \%)$ patient received a second valve implanted within the first valve ("valve in valve") owing to relevant transvalvular regurgitation. There was no conversion to conventional surgery. Concomitant coronary artery disease was treated during the same procedure by elective stent implantation into the right coronary artery in 3 $(14 \%)$ patients and by stent implantation into a narrowed vein graft to the circumflex artery in $1(5 \%)$ patient. The primary result of coronary intervention was good in all patients. One patient received off-pump bypass grafting of the left internal thoracic artery to the left anterior descending artery via a median sternotomy. Transapical aortic valve implantation was performed in this case via an additional $1-\mathrm{cm}$ left subcostal incision that was further used to place a tube into the pleural cavity. Elective femorofemoral CPB was applied in $9(43 \%)$ patients with severe cardiogenic shock and/or poor left ventricular function (LVEF, 10\%-20\%). The mean duration of CPB was $27.4 \pm 24.6$ minutes, with a range from 6 to 81 minutes (Figure 2). In a further 2 $(10 \%)$ patients, cannulas were placed and connected without starting up the heart-lung machine. In 1 of them, who had chronic Leriche syndrome, the left axillary artery was exposed and cannulated. There was neither unexpected nor emergency use of the heart-lung machine.

At the end of the procedure, $15(71 \%)$ patients were receiving catecholamine therapy. The mean dosage of epinephrine was $0.15 \pm 0.11 \mu \mathrm{g} \cdot \mathrm{kg}^{-1} \cdot \mathrm{min}^{-1}$, with a range from 0.05 to $0.36 \mu \mathrm{g} \cdot \mathrm{kg}^{-1} \cdot \mathrm{min}^{-1}$.

The mean fluoroscopy time for the whole group was 11.7 \pm 5.7 minutes (range, 5.3-24.5 minutes). The mean dose area product for the whole group was $7213 \pm 2407 \mu \mathrm{Gy}$

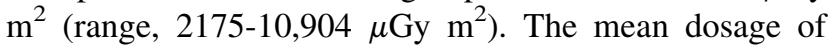
the contrast agent iopromide (ULTRAVIST-370; Bayer 

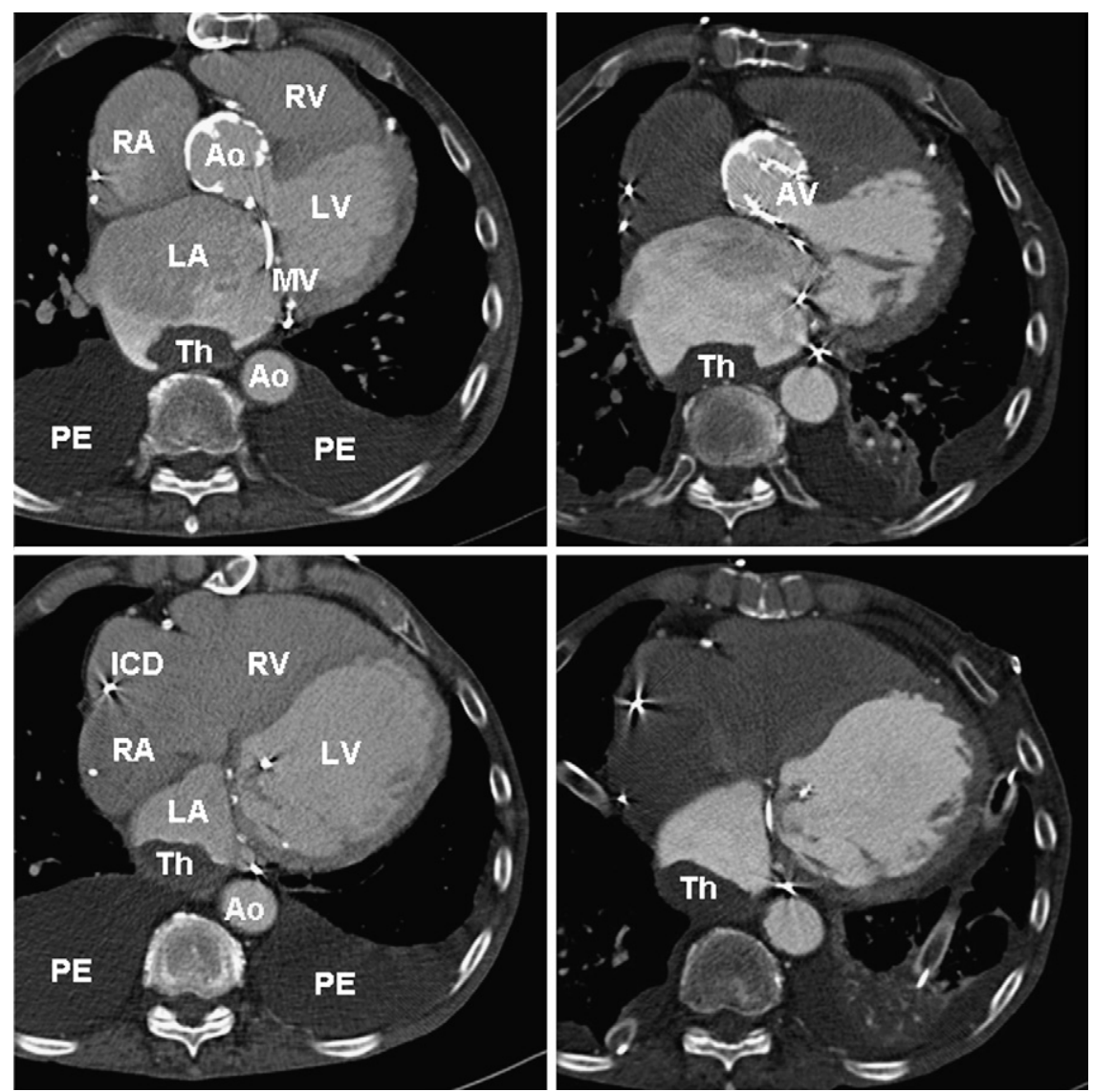

FIGURE 1. Computed tomographic scans of the chest before (left side) and 1 week after transapical aortic valve implantation (right side) in a 75-year-old male patient with advanced biventricular heart failure, porcelain aorta, severe tricuspid valve regurgitation, previous cardiodefibrillator implantation (ICD), and thrombus formation in the giant left atrium. The patient underwent replacement of the aortic valve and aortic root (28-mm homograft) owing to aortic valve stenosis, endocarditis, and annular abscess formation 13 years before. A biological mitral valve replacement (33-mm Hancock) was performed 2 years previously. Transapical aortic "valve-in-valve" implantation was performed under cardiopulmonary bypass (CPB) of short duration (13 minutes) after femorofemoral cannulation. Left ventricular ejection fraction $(L V E F)$ increased from $20 \%$ preoperatively to $40 \%$ postoperatively. Functional New York Heart Association class improved from stage IV preoperatively to stage II 8 months after transapical aortic valve implantation. $P E$, Pleural effusion; $R V$, right ventricle; $R A$, right atrium with ICD lead; $A o$, aorta with circumferential calcification of the implanted homograft; $L V$, enlarged left ventricle; $L A$, giant left atrium with adherent thrombus ( $T h) ; M V, 33-\mathrm{mm}$ Hancock prosthesis; $A V, 26-\mathrm{mm}$ SAPIEN prosthesis.

AG, Leverkusen, Germany) for aortic valve implantation in the whole group was $92 \pm 33 \mathrm{~mL}$ (range, $38-139 \mathrm{~mL}$ ).

\section{Intraoperative Echocardiographic Data in Group I}

Aortic valve stenosis was eliminated in all patients. The mean transvalvular gradient reduced from $33.1 \pm 13.5$ $\mathrm{mm} \mathrm{Hg}$ (range, $10-57 \mathrm{~mm} \mathrm{Hg}$ ) in preoperative transthoracic echocardiography to $4.6 \pm 1.8 \mathrm{~mm} \mathrm{Hg}$ (range, $1.5-7.8 \mathrm{~mm}$ $\mathrm{Hg}$ ) in postoperative transesophageal echocardiography. At the end of the procedure, there was no aortic valve regurgitation in $11(52 \%)$ patients, only trace or mild regurgitation ( $\leq$ grade I) in $9(43 \%)$ patients, and mild regurgitation (grade I-II) in $1(5 \%)$ patient.

\section{In-Hospital Follow-up in Group I}

The mean in-hospital stay at our institution was $17.5 \pm$ 12.3 days, with a range from 5 days to 41 days. All survivors of this period were transferred to an associated general hospital before discharge home or to a rehabilitation clinic. After passing the 30-day interval, 2 patients died in our hospital on day 33 and day 49 owing to septicemia and pneumonia. The mean stay on the intensive care unit was $5.9 \pm 8.2$ days (range, 1-33 days). After that, 10 (48\%) patients were further treated on an intermediate care unit for another 2 to 38 days.

The weaning from catecholamine support was uneventful in all 15 patients and weaning from intra-aortic balloon counterpulsation was uneventful in all 3 patients. The weaning from the respirator was prolonged (ie, lasted $>24$ hours) in $4(19 \%)$ patients. In another $4(19 \%)$ patients, reintubation followed by percutaneous tracheostomy was performed owing to general weakness or ongoing pneumonia. There was no new-onset acute renal failure requiring hemodialysis during the postoperative course. There were also no new 

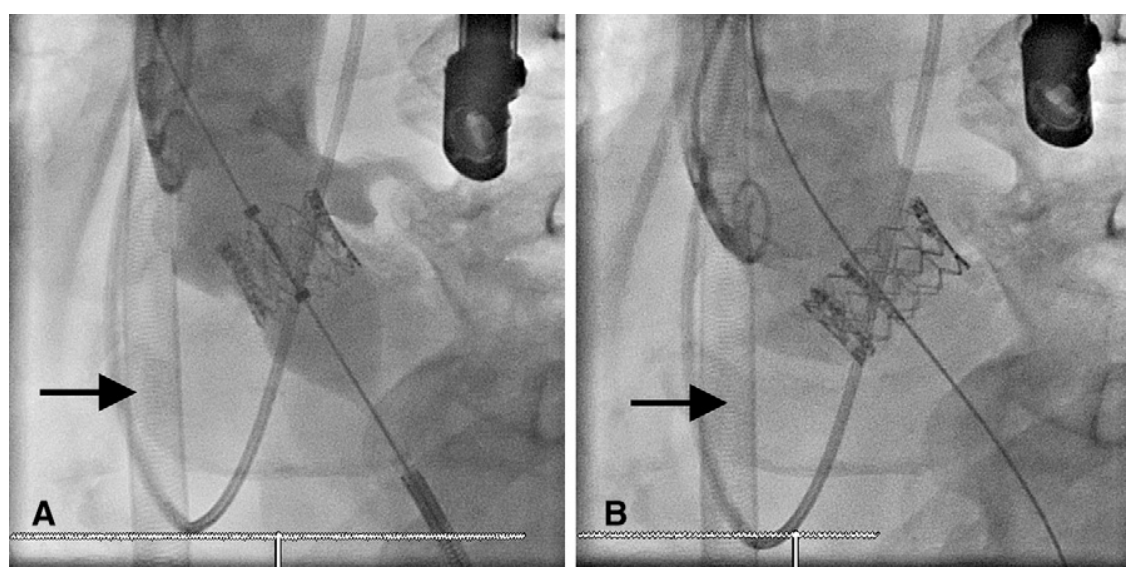

FIGURE 2. A,Valve deployment according to the "Berlin-addition technique" ${ }^{20}$ under short duration of cardiopulmonary bypass (black arrow, venous cannula). B, Angiographic results after transapical aortic valve implantation. The patient was preoperatively in cardiogenic shock, in acute renal failure with severe metabolic acidosis, and dependent on epinephrine and intra-aortic balloon counterpulsation.

clinical signs of stroke after the procedure. A permanent pacemaker was implanted in $2(10 \%)$ patients on days 1 and day 20 , respectively, after transapical aortic valve implantation. There was $1(5 \%)$ patient with severe peripheral arterial disease in whom leg ischemia developed; a percutaneous angioplasty of the right anterior tibial artery was performed 1 week after transapical aortic valve implantation. In $1(5 \%)$ patient with decompensated heart failure, anasarca, and ascites, abdominal puncture to drain ascites was repeatedly performed. Another $(5 \%)$ patient with cardiogenic shock, acute renal failure, anasarca, and recurrent pleural effusion had hemothorax of the right side about 1 month after transapical aortic valve implantation for unknown reasons. The hematoma was uneventfully removed through a right-anterior minithoracotomy.

A significant improvement in left ventricular performance was observed by transthoracic echocardiography within 2 weeks after aortic valve implantation (Figure 3). LVEF increased significantly $(P<.001)$ from $20.4 \% \pm$ $5.3 \%$ (range, $10 \%-25 \%$ ) preoperatively to $38.4 \% \pm$ $11.5 \%$ (range, $20 \%-60 \%$ ) postoperatively. Left ventricular end-diastolic diameter remained unchanged $(P=.291)$ : $57.3 \pm 8.6 \mathrm{~mm}$ (range, $47-80 \mathrm{~mm}$ ) preoperatively versus $55.6 \pm 8.6 \mathrm{~mm}$ (range, $35-73 \mathrm{~mm}$ ) postoperatively.

\section{Late Survival}

The survival in group I at $1,3,6,12,18$, and 24 months was $95 \% \pm 5 \%, 81 \% \pm 9 \%, 76 \% \pm 9 \%, 76 \% \pm 9 \%$, $62 \% \pm 12 \%$, and $62 \% \pm 12 \%$, respectively. The survival in the control group II at $1,3,6,12,18$, and 24 months was $95 \% \pm 1 \%, 89 \% \pm 2 \%, 85 \% \pm 3 \%, 82 \% \pm 3 \%, 78 \% \pm$ $4 \%$, and $62 \% \pm 7 \%$, respectively. There were no statistically significant differences between the 2 groups $(P=.207)$. The Kaplan-Meier survival function is given in Figure 4. An LVEF of $25 \%$ or lower per se was not found to be a significant predictor for midterm survival in the univariate analysis $(P=.206)$.

\section{DISCUSSION \\ Favorable Outcome}

Our experience with 21 patients with poor left ventricular performance shows that transapical aortic valve implantation
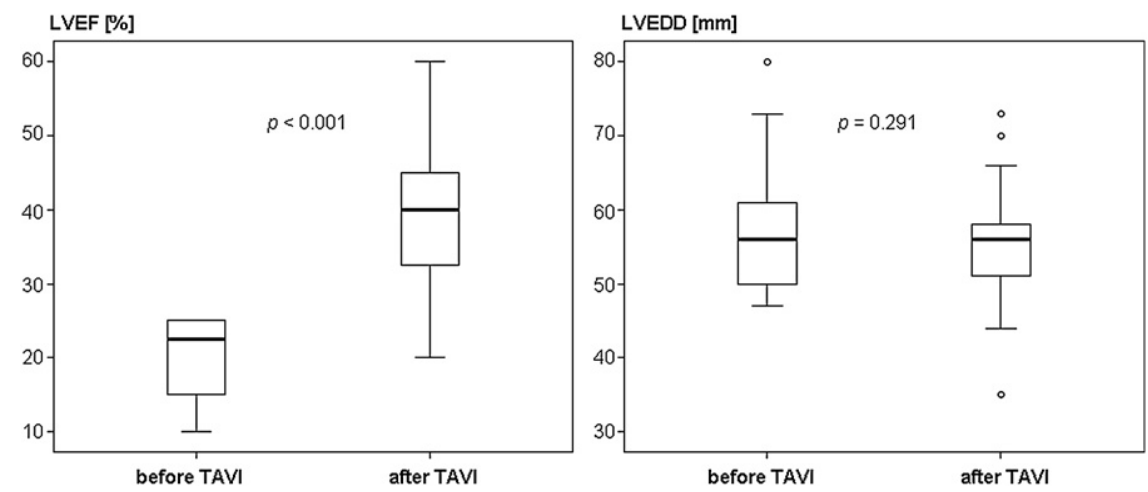

FIGURE 3. Left ventricular ejection fraction $(L V E F)$ and end-diastolic diameter $(L V E D D)$ in 21 patients with poor left ventricular performance (LVEF $\leq 25 \%$ ) before and after transapical aortic valve implantation (TAVI). LVEF improved significantly up to 2 weeks after TAVI from $20.4 \% \pm 5.3 \%$ to $38.4 \% \pm 11.5 \%$. LVEDD remained unchanged: $57.3 \pm 8.6 \mathrm{~mm}$ preoperatively and $55.6 \pm 8.6 \mathrm{~mm}$ postoperatively. 


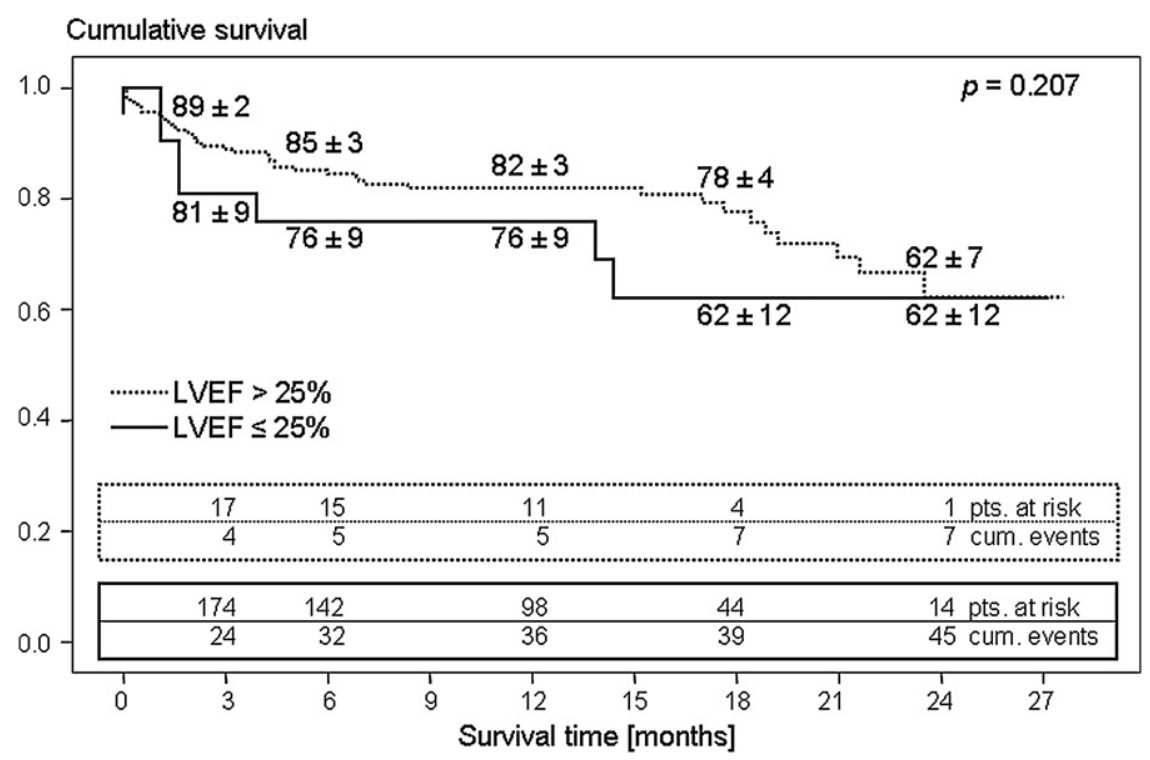

FIGURE 4. The Kaplan-Meier survival function for 21 patients with a left ventricular ejection fraction (LVEF) between $10 \%$ and $25 \%$ (solid line) and for 237 patients with an LVEF above $25 \%$ (dotted line).

is a technically feasible, simple, and safe procedure under these critical circumstances. The early results with a 30day mortality of $4.8 \%$ as well as the midterm outcome were excellent. We observed a fast improvement in hemodynamics and left ventricular performance. These results represent a continuation of our excellent early results already achieved during our learning curve. ${ }^{15}$ Furthermore, they have exceeded our expectations in this cohort of patients with a true high risk for conventional aortic valve replacement. In comparison with other therapeutic strategies - that is, only medical management or balloon valvuloplasty ${ }^{6}$ - much better results were achieved. Transapical aortic valve implantation has become de facto our institutional primary choice of treatment in those patients.

\section{Prolonged Recovery}

On the other hand, the postoperative course was prolonged, especially in patients who had decompensated heart failure and profound shock. The stay on the intensive care unit was especially prolonged and respiratory complications occurred more often. Almost all complications were related to the preoperative decompensated stage and impaired function of other organs. One may conclude from this that patients should be treated early and electively rather than on an emergency basis or in the chronic stage of congestive heart failure. Vice versa, despite the technical aspects of implantation, success by transapical aortic valve implantation can be achieved only if there is a highly specialized team on the intensive care unit taking care of this specific group of patients 24 hours a day. Respiratory therapists on the intensive care unit are another prerequisite for successful weaning from the respirator and to prevent the occurrence of associated pneumonia. Furthermore, the prolonged stay on the intensive care unit was for safety reasons; some patients were transferred arbitrarily a few days later than other patients to the normal ward, although recompensation had already been achieved.

\section{Role of CPB}

CPB is rarely necessary for transcatheter aortic valve implantation, but it is a prerequisite for the procedure to have the heart-lung machine ready to use in the operating room and it is an important part of the safety net. ${ }^{19}$ Furthermore, its elective use may increase the safety in critically ill patients, especially during the learning curve. ${ }^{15}$ We consider the use of the heart-lung machine in the following 3 ways: (1) placement of the connecting tubes on the table, (2) cannulation of the femoral vessels without starting up the heart-lung machine, and (3) valvuloplasty and valve deployment under a short duration of CPB. The first strategy may save time if complications occur. We use it, for instance, in patients with a small distance of the coronary ostia to the aortic annulus or in patients with severe pulmonary hypertension. The second strategy seems to be justified in patients with markedly reduced left ventricular function (ie, $\mathrm{LVEF}<25 \%$ ) or severe regurgitation of the atrioventricular valves. If hemodynamic instability (refractory to high-dose catecholamine application) occurs, the heartlung machine may be started within 1 second after simply removing the clamps on the connecting tubes. The third strategy is considered at our institution in patients with poor left ventricular performance (LVEF 10\%-20\%), in the presence of cardiogenic shock, and in patients with decompensated right-sided heart failure with enlarged right 
ventricle. The progression of rapid pacing into ventricular fibrillation is often difficult to manage. Primary use of CPB instead of its secondary use on an emergency basis provides superior results. On the other hand, transapical aortic valve implantation with the safety of the heart-lung machine is a very simple way to eliminate aortic valve stenosis in these critically ill patients. From our initial experience, it seems to provide much better early results in comparison with conventional aortic valve replacement, which carries a relatively high operative mortality in these specific patients. ${ }^{3}$

\section{Myocardial Recovery}

A poor LVEF of $25 \%$ or below immediately before the procedure was not associated with a poorer prognosis. Despite a longer recovery period in patients with an LVEF of $10 \%$ to $25 \%$, midterm outcome did not differ from that of patients with an LVEF higher than $25 \%$. We observed a 1 -year survival of $76 \%$ (LVEF $\leq 25 \%$ ) and $82 \%$ (LVEF $>25 \%$ ) and a 2-year survival of $62 \%$ in both subgroups. This emphasizes that in these polymorbid and mostly elderly patients, life-expectancy in the midterm follow-up is limited even after complete elimination of aortic valve stenosis and is further determined by other diseases regardless of the ejection fraction in the decompensated stage preoperatively.

LVEF increased from $20 \%$ to $38 \%$. If there was a myocardial contractility reserve, left ventricular performance was restored quickly after elimination of aortic valve stenosis. Transapical aortic valve implantation in these very high-risk patients can be performed safely when the whole repertoire of cardiac surgery is applied, including the use of the heart-lung machine in some of these specific cases. The use of intra-aortic balloon counterpulsation may support myocardial recovery. We consider its elective use in patients with cardiogenic shock and significant catecholamine support after valve implantation. We observed a lower LVEF in preoperative transesophageal echocardiography compared with transthoracic echocardiography a few days before the procedure in some patients. Since decompensation is an ongoing process, estimation of left ventricular performance by transesophageal echocardiography immediately before the procedure is mandatory in our experience.

\section{CONCLUSIONS}

This study confirms in a cohort of 21 patients that transapical aortic valve implantation is a feasible method to treat patients with poor left ventricular performance, advanced heart failure, or cardiogenic shock. The advantage of the hybrid procedure is its lesser invasiveness compared with conventional surgery that carries the additional myocardial trauma of cardioplegic cardiac arrest. If the excellent early results are confirmed in a larger group of patients, this method may become the standard therapy to treat aortic valve stenosis in the presence of decompensated heart failure. Indeed, transapical aortic valve implantation was much more than an ultima-ratio attempt in our patients who had a high risk for conventional aortic valve replacement.

A major limitation of the present study is the limited number of patients and a relatively short follow-up interval. A close follow-up is necessary for each of them. Beside further close observations of clinical signs of heart failure, the left ventricular performance needs to be evaluated by echocardiography in the longer follow-up.

Other members of the TAVI team are Dr Alexander Mladenow, Dr Christoph Klein, and Katrin Schäfer. We thank Anne Gale for editorial assistance and Julia Stein for statistical analyses.

\section{References}

1. Brown JM, O'Brien SM, Wu C, Sikora JA, Griffith BP, Gammie JS. Isolated aortic valve replacement in North America comprising 108,687 patients in 10 years: changes in risks, valve types, and outcomes in the Society of Thoracic Surgeons National Database. J Thorac Cardiovasc Surg. 2009;137:82-90.

2. Vaquette B, Corbineau H, Laurent M, Lelong B, Langanay T, de Place C, et al. Valve replacement in patients with critical aortic stenosis and depressed left ventricular function: predictors of operative risk, left ventricular function recovery, and long term outcome. Heart. 2005;91:1324-9.

3. Clavel MA, Fuchs C, Burwash IG, Mundigler G, Dumesnil JG, Baumgartner H, et al. Predictors of outcomes in low-flow, low-gradient aortic stenosis: results of the multicenter TOPAS Study. Circulation. 2008;118:S234-42.

4. Doguet F, Godin M, Lebreton G, Eltchaninoff H, Cribier A, Bessou JP, et al. Aortic valve replacement after percutaneous valvuloplasty - an approach in otherwise inoperable patients. Eur J Cardiothorac Surg. 2010;38(4):394-9.

5. Gregoric ID, Loyalka P, Radovancevic R, Jovic Z, Frazier OH, Kar B. TandemHeart as a rescue therapy for patients with critical aortic valve stenosis. Ann Thorac Surg. 2009;88:1822-6.

6. Ben-Dor I, Pichard AD, Gonzalez MA, Weissman G, Li Y, Goldstein SA, et al. Correlates and causes of death in patients with severe symptomatic aortic stenosis who are not eligible to participate in a clinical trial of transcatheter aortic valve implantation. Circulation. 2010;122:S37-42.

7. Cribier A, Eltchaninoff H, Bash A, Borenstein N, Tron C, Bauer F, et al. Percutaneous transcatheter implantation of an aortic valve prosthesis for calcific aortic stenosis: first human case description. Circulation. 2002;106:3006-8.

8. Grube E, Laborde JC, Gerckens U, Felderhoff T, Sauren B, Buellesfeld L, et al. Percutaneous implantation of the CoreValve self-expanding valve prosthesis in high-risk patients with aortic valve disease: the Siegburg first-in-man study. Circulation. 2006;114:1616-24.

9. Lichtenstein SV, Cheung A, Ye J, Thompson CR, Carere RG, Pasupati S, et al. Transapical transcatheter aortic valve implantation in humans: initial clinical experience. Circulation. 2006;114:591-6.

10. Walther T, Simon P, Dewey T, Wimmer-Greinecker G, Falk V, Kasimir MT, et al. Transapical minimally invasive aortic valve implantation: multicenter experience. Circulation. 2007;116(11 Suppl):I240-5.

11. Bleiziffer S, Ruge H, Mazzitelli D, Hutter A, Opitz A, Bauernschmitt R, et al. Survival after transapical and transfemoral aortic valve implantation: talking about two different patient populations. J Thorac Cardiovasc Surg. 2009;138: 1073-80.

12. Rodés-Cabau J, Webb JG, Cheung A, Ye J, Dumont E, Feindel CM, et al. Transcatheter aortic valve implantation for the treatment of severe symptomatic aortic stenosis in patients at very high or prohibitive surgical risk: acute and late outcomes of the multicenter Canadian experience. J Am Coll Cardiol. 2010;55: 1080-90.

13. Thomas M, Schymik G, Walther T, Himbert D, Lefèvre T, Treede H, et al. Thirtyday results of the SAPIEN aortic Bioprosthesis European Outcome (SOURCE) Registry: a European registry of transcatheter aortic valve implantation using the Edwards SAPIEN valve. Circulation. 2010;122:62-9.

14. Walther T, Schuler G, Borger MA, Kempfert J, Seeburger J, Rückert Y, et al. Transapical aortic valve implantation in 100 consecutive patients: comparison to propensity-matched conventional aortic valve replacement. Eur Heart J. 2010;31:1398-403. 
15. Pasic M, Unbehaun A, Dreysse S, Drews T, Buz S, Kukucka M, et al. Transapical aortic valve implantation in 175 consecutive patients: excellent outcome in very high-risk patients. J Am Coll Cardiol. 2010;56:813-20.

16. Drews T, Pasic M, Buz S, Unbehaun A, Dreysse S, Kukucka M, et al. Transapical aortic valve implantation after previous heart surgery. Eur J Cardiothorac Surg. 2011;39:625-30.

17. Ye J, Cheung A, Lichtenstein SV, Nietlispach F, Albugami S, Masson JB, et al. Transapical transcatheter aortic valve implantation: follow-up to 3 years. $J$ Thorac Cardiovasc Surg. 2010;139:1107-13.
18. Yan TD, Cao C, Martens-Nielsen J, Padang R, Ng M, Vallely MP, et al. Transcatheter aortic valve implantation for high-risk patients with severe aortic stenosis: a systematic review. J Thorac Cardiovasc Surg. 2010;139:1519-28.

19. Walther T, Dewey T, Borger MA, Kempfert J, Linke A, Becht R, et al. Transapical aortic valve implantation: step by step. Ann Thorac Surg. 2009;87: 276-83.

20. Pasic M, Dreysse S, Drews T, Buz S, Unbehaun A, Kukucka M, et al. Improved technique of transapical aortic valve implantation: "the Berlin addition." Ann Thorac Surg. 2010;89:2058-60. 